\title{
CONSIDERAÇÕES SOBRE A INCONSTITUCIONALIDADE DO §2 DO ART. 414 DO CÓDIGO TRIBUTÁRIO DO MUNICÍPIO DE SÃO LUÍS DE 2017
}

\author{
Fabiano Ferreira Lopes*1 \\ Leonardo Albuquerque Marques**2
}

Resumo: O presente trabalho pretende refletir sobre a aplicação do tratamento diferenciado na imposição do Imposto sobre Serviços de Qualquer Natureza (ISSQN), nos termos da Lei $n^{0}$ 6.289, de 28 de dezembro de 2017, que instituiu o Código Tributário do Município de São Luís (CTM/SLZ), aos profissionais intelectuais que exercem sua atividade de forma individual em comparação aos que exercem por meio de sociedade. Ao final, foi possível constatar que há inconstitucionalidade no $\S 2^{\circ}$ do art. 414 do CTM/SLZ por ferir o Princípio da Isonomia Tributária.

Palavras-Chaves: ISSQN; Princípio Da Isonomia Tributária; Profissional Intelectual; Profissional Liberal; Inconstitucionalidade

\section{CONSIDERATIONS ON THE UNCONSTITUTIONALITY OF SECTION 2 OF ART. 414 OF THE TAX CODE OF THE MUNICIPALITY OF SÃO LUÍS, 2017}

\begin{abstract}
This article is about the application of differential treatment in the imposition of the Tax on Services of any Nature (ISSQN), under the terms of Law no. 6.289, of December 28, 2017, which established the Tax Code of the Municipality of São Luís (CTM/SLZ), to the intellectual professionals who exercise their activity individually to the detriment of those who exercise it through a society of professionals. In the end, it was possible to verify that there is unconstitutionality in $\S 2$ of art. 414 of the CTM / SLZ for violating the Principle of Tax Isonomy.
\end{abstract}

Keywords ISSQN; Principle Of Tax Isonomy; Intellectual Professionals; Liberal Professionals; Unconstitutionality

\footnotetext{
1 * Mestre em Administração e Controladoria pelo Programa de Pós-Graduação em Administração e Controladoria da Universidade Federal do Ceará. Especialista em Direito Tributário pela Fundação Getúlio Vargas. Especialista em Direito Processual Civil pela Universidade CEUMA. Especialista em Auditoria e Controladoria pela Universidade Gama Filho. Professor e Pesquisador-lider do Núcleo de Estudos sobre Orçamento, Finanças e Tributação da Universidade Federal do Maranhão. Advogado. Contador. E-mail: fabiano@fabianolopes.com. Endereço profissional: Av. Colares Moreira, Ed. Business Center, Sala 816, São Luís, MA, CEP 65.075-441.

2 ** Doutor em Direito pela Pontifícia Universidade Católica de São Paulo. Membro associado da Associação Brasileira de Direito e Economia. Membro da ANNEP - Associação Norte e Nordeste de Professores de Processo. Professor da graduação e da pós-graduação da Universidade CEUMA. Advogado. E-mail: leonardoamarques@hotmail.com. Endereço profissional: Universidade CEUMA, Rua Josué Montello, no 1, Renascença II, São Luís, MA, CEP 65.075-120.
} 


\section{INTRODUÇÃO}

Com o advento da Lei Complementar nº 157, de 29 de dezembro de 2016, o Imposto sobre Serviço de Qualquer Natureza (ISSQN) recebeu atenção especial por parte das municipalidades, em especial, por causa da atualização da lista de serviços em que incide o referido imposto.

O município de São Luís, estado do Maranhão, visando atualizar o seu Código Tributário Municipal publicou em 28 de dezembro de 2017 a Lei $n^{\circ} 6.289$ que, além de consolidar a legislação tributária municipal esparsa, acabou eivando de inconstitucionalidade a tributação incidente sobre sociedades de profissionais, a saber, sociedades em nome coletivo.

Este artigo visa esclarecer sobre a isonomia entre profissionais intelectuais que exercem suas atividades econômicas de forma individual ou em sociedade em nome coletivo e a incidência do ISSQN em sua forma fixa.

O objetivo geral deste trabalho é analisar a constitucionalidade da Lei ${ }^{\circ} 6.289$, de 28 de dezembro de 2017, que instituiu o Código Tributário do Município de São Luís, estado do Maranhão, quanto à incidência do Imposto Sobre Serviços de Qualquer Natureza aos profissionais intelectuais que exercem suas atividades econômicas de forma individual em comparação àqueles que a exercem por meio de sociedade em nome coletivo.

Neste sentido, pode-se classificar a presente pesquisa como sendo uma pesquisa aplicada, no que atine à sua natureza, uma vez que, para SILVA e MENEZES (2001), a pesquisa gera conhecimento para aplicação à solução de um problema específico; no que atine ao objetivo, a pesquisa é explicativa, por visar identificar os fatores que determinam ou contribuem para a ocorrência dos fenômenos; e, por fim, é uma pesquisa qualitativa, haja vista que visa constatar a relação dinâmica entre o mundo real e o sujeitos, por meio da interpretação dos fenômenos e a atribuição de significados.

A pesquisa foi realizada por meio de fontes secundárias com a investigação da legislação tributária, posições doutrinárias e jurisprudência que envolvem o tema, sendo classificada quanto ao procedimento, uma pesquisa de caráter bibliográfico. (SILVA e MENEZES, 2001) 


\section{CONSIDERAÇÕES SOBRE A INCONSTITUCIONALIDADE DO §2 DO ART. 414 DO \\ CÓDIGO TRIBUTÁRIO DO MUNICÍPIO DE SÃO LUÍS DE 2017}

As hipóteses consideradas para o presente estudo são duas, a saber: o profissional intelectual que exerce sua atividade econômica por meio de sociedade de profissionais não se diferencia daquele que exerce de forma individual; e o Código Tributário do Município de São Luís, Estado do Maranhão, está eivado de inconstitucionalidade material no que atine ao tratamento tributário do ISSQN fixo para profissionais liberais.

O artigo está estruturado em 3 (três) seções, sendo que, na primeira seção, tenta-se apresentar a equivalência, em termos de responsabilidade, da prestação de serviços realizada por profissional intelectual quando atua em sociedade de profissionais e de forma individual.

Na segunda seção, o foco está na incidência do ISSQN na prestação de serviços realizada por profissionais intelectual conforme a doutrina e jurisprudência nacional, em especial, no entendimento sumulado pelo Supremo Tribunal Federal.

Por fim, na terceira seção, busca-se demonstrar a inconstitucionalidade do Código Tributário do Município de São Luís, estado do Maranhão, no que atine ao tratamento tributário desigual dado aos profissionais intelectuais que atuam em sociedade de profissionais, logo, ferindo princípio da isonomia tributária.

\section{DO PROFISSIONAL INTELECTUAL, DA SOCIEDADE DE PROFISSIONAIS E A RESPONSABILIDADE DO EXERCÍCIO DA ATIVIDADE ECONÔMICA}

Os profissionais intelectuais ${ }^{3}$ em regra não podem ser considerados empresários, uma vez que, conforme preceitua o Código Civil, no parágrafo único do art. 966, a saber:

Não se considera empresário quem exerce profissão intelectual, de natureza científica, literária ou artística, ainda como o concurso de

\footnotetext{
${ }^{3}$ RAMOS (2010, p. 62) esclarece que os profissionais intelectuais são chamados, também, de profissionais liberais. Sendo que estes são todos os profissionais que atuam em atividades de alta especialização tais como advogados, médicos, odontólogos, professores e dentre outros.
} 
auxiliares ou colaboradores, salvo se o exercício da profissão constituir elemento de empresa.

O elemento de empresa, conforme TOMAZETTE (2008, p. 46) pode ser entendido quando os serviços do profissional intelectual são absorvidos por uma atividade maior de natureza empresarial, ou seja, perdendo a característica de prestação de serviços pessoais do profissional ao ponto da prestação de ser “apenas um elemento dentro da atividade empresarial exercida”.

Neste sentido, o Enunciado 194 da III Jornada de Direito Civil promovida pelo Conselho da Justiça Federal (CJF) veio a afirmar que "Os profissionais liberais não são considerados empresários, salvo se a organização dos fatores de produção for mais importante que a atividade pessoal desenvolvida”.

No que atine à responsabilidade, conforme preceitua o art. 927 do Código Civil, os profissionais intelectuais acabam por ser responsabilizados ilimitadamente pelas consequências dos atos ilícitos praticados no exercício de sua profissão, uma vez que “Aquele que, por ação ou omissão voluntária, negligência ou imprudência, violar direito e causar dano a outrem, ainda que exclusivamente moral, comete ato ilícito”, como dita o art. 186 do já referida norma.

Assim, no exercício de sua atividade econômica, o profissional intelectual, quando presta serviços de forma pessoal, mesmo que organizadamente com auxiliares, poderá indenizar com a totalidade de seu patrimônio caso venha a gerar perdas a terceiros. Contudo, se o mesmo perder a pessoalidade quando do exercício da prestação de serviços, perderá o profissional intelectual a sua característica civil e será considerado empresário, vindo a ser regulado pelas normas que gerem a atividade empresarial.

A responsabilização ilimitada do profissional intelectual encontra-se presente, também, quando dois ou mais profissionais resolvem constituir uma sociedade de profissionais para atuar em conjunto e sem fazer opção por um determinado tipo societário. Quando isso ocorre, os profissionais constituem uma sociedade em nome coletivo, nos termos do art. 1.039 do Código Civil.

TOMAZETTE (2008, p.317), consegue explicar de forma clara esta situação: 


\section{CONSIDERAÇÕES SOBRE A INCONSTITUCIONALIDADE DO §2음 AO ART. 414 DO \\ CÓDIGO TRIBUTÁRIO DO MUNICÍPIO DE SÃO LUÍS DE 2017}

Se não se consegue distinguir, com segurança, qual o tipo societário, há que se concluir que se trata de uma sociedade em nome coletivo, pela aplicação do princípio do tipo social mais simples ou princípio da prevalência da inqualitariedade social. Ora, se os sócios não definem nenhuma peculiaridade maior para a sociedade, é certo que estaremos diante de sociedade mais simples, que é a sociedade em nome coletivo.

Conforme esclarece RAMOS (2010, p.478-479), a sociedade em nome coletivo é o mais antigo tipo societário, com origem na Idade Média, bem como tendo como principal característica a responsabilidade ilimitada dos sócios que a compõem, sendo que, por ser uma sociedade contratual de pessoas é elemento nuclear a adoção do uso de firma social como espécie de nome empresarial.

Quanto ao uso de firma social por parte das sociedades em nome coletivo, MIRANDA (1984, p.230) ensina que neste tipo de sociedade, a identificação, pelo público em geral, de quais são as pessoas físicas que fazem parte da entidade está diretamente relacionada com a sobrevivência da sociedade. Com efeito, tal tipo societário é uma sociedade de pessoas e não de capital, afastando-se, assim, da natureza de sociedade empresária.

Importante frisar que, salvo a sociedade de advogados, que obrigatoriamente deverá ser na forma sociedade simples pura, conforme preceitua o art. 16 da Lei 8.906, de 04 de julho de 1994, os demais profissionais intelectuais podem constituir sociedade em outras formas societárias que, conforme a natureza que venha a adotar, acabará por ter a sua responsabilidade societária definida pela forma societária que vier a formalizar ${ }^{4}$.

Infere-se que a isonomia entre o profissional intelectual que exerce sua atividade econômica de forma solitária ou em sociedade de profissionais, quando constituída em forma de sociedade em nome coletivo, quando analisa-se o instituto da insolvência civil.

\footnotetext{
${ }^{4}$ RAMOS (2010, p. 309-505) ensina que a definição da forma societária é que determinará a extensão da responsabilidade do sócio. Desta forma, o enquadramento no que atine à responsabilidade do sócio dependerá de qual tipo societário foi o escolhido pelos sócios para ser formalizado, uma vez que pode a constituição ser feita como sociedade empresária limitada, sociedade anônima (aberta ou fechada), sociedade em nome coletivo, sociedade em comandita simples e sociedade em comandita por ações.
} 
Curiosamente, o art. 1.052 da Lei $\mathrm{n}^{0}$ 13.105, de 16 de março de 2015, (CPC de 2015), que trata sobre as execuções contra devedor insolvente, remete à necessidade de uma lei específica para regulamentar o instituto da insolvência civil e, desta forma, o Livro II, Título IV, da Lei nº 5.869, de 11 de janeiro de 1973, (CPC-1973) não foi revogado.

Nos termos dor art. 748 do CPC-1973 ocorre insolvência civil "toda vez que as dívidas excederem à importância dos bens do devedor”, sendo que, conforme determina o art. 486 do mesmo diploma legal, “as sociedades civis, qualquer que seja a sua forma”, também, são abarcadas por este instituto.

TOMAZETTI (2008, p. 270) esclarece que “as atividades dos profissionais liberais também são consideradas atividades civis (excluídas até da idéia da atividade empresarial, na medida em que inexiste intermediação, além do fator pessoal preponderante para a atividade”. Este mesmo autor esclarece, ainda, que a distinção entre sociedade empresária e sociedade simples (antiga sociedade civil|) torna-se importante, principalmente, para fins de submissão ao instituto da falência, uma vez que aquelas podem requerer recuperação, já estas não podem.

Ao analisar o instituto da insolvência civil e o instituto da recuperação de empresas e falência, nos termos do art. $1^{\circ}$ da Lei 11.101, de 09 de fevereiro de 2005, pode-se constatar que há reconhecimento de idêntico entre aquele que exerce a profissão intelectual como profissional autônomo e aqueles que realizam por meio de sociedade profissionais na forma de sociedade em nome coletivo.

Sobre o assunto, UBALDO (2004, p. 23-38) esclarece que a insolvência civil é um processo de execução autônoma a ser aplicado contra o devedor (pessoa física) quando suas dívidas venham a exceder a importância de seus bens, sendo aplicado, também, em sociedades em nome coletivo, uma vez que é uma sociedade de pessoas e não se aplica nestes casos a lei de falências.

Ratificando precedentes ${ }^{5}$ sobre o tema, em recente julgado, Agravo em Recurso Especial No 1.006.254 - SP (2016/0282555-8), o Ministro Raul Araújo esclareceu que em uma

\footnotetext{
${ }^{5}$ O Tribunal Regional Federal da $3^{\mathrm{a}}$ Região, nos termos do Agravo de Instrumento $\mathrm{n}^{\circ}$ 0025611-76.2013.4.03.000, de relatoria do Desembargador Federal Márcio Moraes, julgado em 03/04/2014 na Terceira Turma, bem como o Tribunal de Justiça de São Paulo, nos termos do Agravo de Instrumento no 0110572-72.2013.8.26.0000, de
} 


\section{CONSIDERAÇÕES SOBRE A INCONSTITUCIONALIDADE DO §2 DO ART. 414 DO \\ CÓDIGO TRIBUTÁRIO DO MUNICÍPIO DE SÃO LUÍS DE 2017}

sociedade empresaria limitada dissolvida irregularmente, por haver confusão patrimonial, acarreta a responsabilização dos sócios de forma ilimitada "à moda de uma sociedade em nome coletivo, onde a responsabilidade de todos os seus integrantes é absoluta”.

Sendo assim, por meio de vasta doutrina e jurisprudência, evidenciou-se que não há distinção entre profissionais liberais que exercem sua atividade econômica em caráter individual ou em forma de sociedade de profissionais, quando revestida de sua forma simples, ou seja, em forma de sociedade em nome coletivo, uma vez que os efeitos quanto a responsabilidade são ilimitados em ambas as formas de exercer a profissão.

Superados os esclarecimentos desta seção, passa-se a discorrer sobre o imposto municipal que incide na prestação de serviços de profissionais intelectuais, ou seja, profissionais liberais.

\section{O ISSQN NA PRESTAÇÃO DE SERVIÇOS REALIZADA POR PROFISSIONAIS INTELECTUAIS}

O Imposto sobre Serviços de Qualquer Natureza, nos termos do inciso III do art. 153 da Constituição da República de 1988, é um imposto municipal que suas normas gerais para efeitos nacionais definidos pela Lei Complementar $n^{0}$ 116, de 31 de julho de 2003, (LC 116/03) e no Decreto Lei no 406, de 31 de dezembro de 1968 (DL 406/68).

SABAAG (2015, p. 1115) esclarece que o art. $7^{\circ}$ da LC 116/03 deixa claro que o ISSQN deve ser cobrado com base no valor bruto dos serviços, sendo que, nos casos em que não se possa aferir o valor correspondente do serviço, como é o caso daqueles prestados por profissionais liberais, o cálculo do tributo será feito a partir de um único valor periodicamente. O autor ensina, ainda, que "nesse caso, teremos um ISS fixo, sendo impróprio falar em grandezas quantificadoras do fato gerados, como alíquota e a própria base de cálculo”.

relatoria do Juiz Luiz Ambra, julgado em 14/08/2013, são uníssonos quanto a aplicação do instituto da insolvência civil e do alcance ilimitado ao patrimônio do sócios de sociedade em nome coletivo. 
O cálculo diferenciado do ISSQN aplicável aos profissionais liberais, atuando isoladamente ou por meio de sociedade de profissionais, é feito por valores fixos, como descrito anteriormente, baseado nos $\S \S 1^{\circ}$ e $3^{\circ}$ do Art. $9^{\circ}$ do Decreto-Lei $n^{\circ} 406$, de 31 de dezembro de 1968, que tem a seguinte redação:

Art $9^{\circ}$ A base de cálculo do imposto é o preço do serviço.

$\S 1^{\circ}$ Quando se tratar de prestação de serviços sob a forma de trabalho pessoal do próprio contribuinte, o imposto será calculado, por meio de alíquotas fixas ou variáveis, em função da natureza do serviço ou de outros fatores pertinentes, nestes não compreendida a importância paga a título de remuneração do próprio trabalho.

$\S 3^{\circ}$ Quando os serviços a que se referem os itens 1, 4, 8, 25, 52, 88, 89, 90, 91 e 92 da lista anexa forem prestados por sociedades, estas ficarão sujeitas ao imposto na forma do $\S 1^{\circ}$, calculado em relação a cada profissional habilitado, sócio, empregado ou não, que preste serviços em nome da sociedade, embora assumindo responsabilidade pessoal, nos termos da lei aplicável.

O STF e o STJ já foram questionados por diversas ${ }^{6}$ municipalidades quanto ao tratamento diferenciado dado ao profissional autônomo, exercendo em caráter individual ou por meio de sociedade de profissionais, para que o mesmo viesse a pagar o ISSQN em valores fixos e não pela regra geral, ou seja, pela apuração do imposto pela proporcionalidade com base no preço do serviço prestado. Destas discussões, resultou o entendimento o entendimento jurisprudencial cristalizado na Súmula 663 do STF que esclarece que “Os $\S \S 1^{\circ}$ e $3^{\circ}$ do art. $9^{\circ}$ do DL 406/68 foram recepcionados pela Constituição”

Em suma, o STF e o STJ firmaram que o tratamento diferenciado, nos termos dos $\S \S 1^{\circ}$ e $3^{\circ}$ do Art. $9^{\circ}$ do Decreto-Lei $n^{\circ} 406$, de 31 de dezembro de 1968, só não é aplicado quando ausentes um dos seguintes requisitos:

\footnotetext{
${ }^{6}$ Os municípios de Curitiba (RE 236604-7/PR e RE 24941-9/PR), Belo Horizonte (RE 220323-3/MG e RE 228052-9/MG) e Porto Alegre (RE 99266-9/RS), por exemplo, tiveram seus Códigos Tributários Municipais questionados quanto aos critérios exigidos pelos parágrafos $1^{\circ}$ e $3^{\circ}$ do art. $9^{\circ}$ do Decreto Lei $n^{\circ} 406 / 68$. 31 de dezembro de 1968.
} 
a) Pessoalidade do trabalho dos profissionais habilitados;

b) Ausência de empresariedade na constituição e no funcionamento da sociedade;

c) Uniprofissionalidade e especialização da sociedade de profissionais;

d) Responsabilidade pessoal e ilimitada do profissional na prestação do serviço.

Nestes termos, quando uma sociedade de profissionais intelectuais é constituída na forma simples em nome coletivo, o pagamento do ISSQN deverá ser feito por profissional liberal habilitado, sócio, empregado ou não, que preste serviços em nome da sociedade e não pela proporcionalidade do preço do serviço, que é a regra geral nos termos do art. $7^{\circ}$ da Lei Complementar $\mathrm{n}^{\circ}$ 116, de 31 de julho de 2003.

Passa-se, agora, aos esclarecimentos quanto a inconstitucionalidade da Lei $\mathrm{n}^{\circ}$ 6.289, de 28 de dezembro de 2017, Código Tributário do Município de São Luís (CTM/SLZ), em especial, a parte final do $\S 2^{\circ}$ do art. 414.

\section{DA INCONSTITUCIONALIDADE QUANTO A VIOLAÇÃO AO PRINCÍPIO DA IGUALDADE TRIBUTÁRIA}

Na seção anterior demonstrou-se que não há distinção jurídica entre o profissional autônomo que exerce sua atividade econômica em caráter individual em relação àquele que a exerça em sociedade de profissionais, a saber com nomen in iuris sociedade em nome coletivo, sendo esta demonstração elemento para sustentar, na presente seção, a inconstitucionalidade do $\S 2^{\circ}$ do art. 414 da Lei $n^{\circ}$ 6.289, de 28 de dezembro de 2017, Código Tributário do Município de São Luís (CTM/SLZ), em face do princípio da isonomia tributária ${ }^{7}$.

O CTM/SLZ trata sobre Imposto Sobre Serviços de Qualquer Natureza - ISSQN em seu Livro Segundo, Título III, nos artigos 387 a 464, sendo que, para fins do presente artigo,

\footnotetext{
${ }^{7}$ O princípio da isonomia tributária é tratado no Art. 150, II da Constituição da República de 1988 que, pelo princípio da simetria federativa, tem sua reprodução no art. 124, II da Constituição do Estado do Maranhão e no art. 107, II da Lei Orgânica do Município de São Luís.
} 
constata-se que está eivada de inconstitucionalidade a parte final do $\S 2^{\circ}$ do art. 414 da já referida norma.

Para melhor visualização, apresenta-se o dispositivo com destaque ao trecho, em que a inconstitucionalidade está presente:

Art. 414. O Imposto Sobre Serviços de Qualquer Natureza - ISSQN é devido em conformidade com as seguintes alíquotas e valores:

I - profissionais autônomos, em geral:

a) profissionais de nível elementar: $\mathrm{R} \$$ 50,00 (cinquenta reais) por mês;

b) profissionais de nível médio: R\$ 100,00 (cem reais) por mês;

c) profissionais de nível superior: $\mathrm{R} \$ 200,00$ (duzentos reais) por mês:

II - empresas: 5\% (cinco por cento) sobre o valor do serviço, por mês.

$\S 1^{\circ}$ Quando os serviços forem prestados pelos profissionais especificados no $\S 1^{\circ}$ do art. 413 deste Código, o imposto será devido pela sociedade, por mês, em relação a cada profissional habilitado, seja sócio, empregado ou não, que preste serviço em nome da sociedade, embora assumindo responsabilidade pessoal nos termos da lei regulamentadora da profissão.

$\S 2^{\circ} \mathrm{O}$ imposto a que se refere o $\S 1^{\circ}$ deste artigo será calculado por profissional habilitado, seja sócio, empregado ou não, que preste serviço em nome da sociedade, no valor de RS 684,59 (seiscentos e oitenta e quatro reais e cinquenta e nove centavos) por mês.

$\S 3^{\circ} \mathrm{Na}$ forma do disposto do artigo 10 desta Lei, a Secretaria Municipal de Fazenda, expedirá instrução Normativa com vistas a assegurar os direitos de recolhimento em condições especiais e categorias 
profissionais que possuam decisões judiciais com trânsito em julgado. (Lei ${ }^{\circ}$ 6.289, de 28 de dezembro de 2017) grifo nosso.

O $\S 1^{\circ}$ do art. 414 do CTM/SLZ faz alusão ao art. 413 do mesmo dispositivo legal que descreve quais são atividades econômicas que sofreram a incidência do ISSQN com cálculo do imposto com base em valor fixo e que são:

I - médicos, inclusive análises clínicas, eletricidade médica, radioterapia, ultrassonografia, radiologia, tomografia e congéneres;

II - enfermeiros, obstetras, ortópticos, fonoaudiólogos, protéticos (prótese dentária);

III - médicos veterinários;

IV - contabilidade, auditoria, técnicos em contabilidade e congéneres;

$\mathrm{V}$ - agentes de propriedade industrial;

VI - advogados;

VII - engenheiros, arquitetos, urbanistas e agrónomos;

VIII - dentistas;

IX - economistas:

X - psicólogos

Como pode ser verificado, o profissional liberal que atua isoladamente, nos termos do inciso I do art. 414 do CTM/SLZ fica obrigado a pagar o ISSQN fixo na quantia de R\$ 200,00 (duzentos) reais por mês, enquanto que, um mesmo profissional liberal que exerça sua atividade econômica por meio de sociedade de profissionais, ficará obrigado a pagar R\$ 684,59 (seiscentos e oitenta e quatro reais e cinquenta e nove centavos) por mês, conforme determina o $\S 2^{\circ}$ do art. 414 do CTM/SLZ.

ÁVILA (2009, p.158-159) esclarece que, para afastar a presunção de igualdade entre contribuintes, não basta que os reflexos argumentativos e comprobatórios da estatura constitucional da igualdade sejam explicados, é preciso que sejam justificados; mas para que sejam justificados, não bastam que sejam pressupostos, é preciso a confirmação e a existência de vínculo de pertinência, fundada e conjugada, entre a medida e a finalidade que legitima seu uso. 
Sobre igualdade, CARRAZZA (2010, p. 99-100) ensina que o legislador deve, enquanto descreve a norma jurídica instituidora dos impostos de caráter pessoal, não só escolher os fatos que exibam o conteúdo econômico, como atender às desigualdades próprias das diferentes categorias de contribuintes, sendo que, como demonstrado na seção anterior, não há distinção entre o contribuinte que preste serviço individualmente ou por meio de sociedade simples em nome coletivo, uma vez que, em ambas as forma jurídicas, as responsabilidades são pessoais e ilimitadas quando do exercício da atividade econômica.

SABBAG (2015, p. 133) esclarece que:

O tratamento diferenciado, dispensado pelas normas jurídicas, guarda relação de pertinência lógica com a razão diferencial (motivo de atitude discriminatória), não há que se falar em afronta ao princípio da isonomia. Por outro lado, a adoção de um dado fator de discriminação, sem qualquer correspondência com a lógica racional de diferenciação, colocará em xeque a almejada ideia de igualdade.

Neste sentido, percebe-se que, mesmo não havendo qualquer distinção para o profissional liberal, seja ele atuando individualmente ou em sociedade simples em nome coletivo, há injustiça fiscal explícita decorrente de inconstitucionalidade por ferir o Princípio da Isonomia Tributária determinado no inciso II do art. 150 da Constituição da República de 1988.

\section{CONSIDERAÇÕES FINAIS}

Ao tratar do princípio da isonomia tributária no tratamento depreendido pela Lei $\mathrm{n}^{\circ}$ 6.289, de 28 de dezembro de 2017, quanto à incidência do ISSQN sobre a atividade dos profissionais intelectuais - profissionais liberais - objetivou-se constatar se há características distintivas que venham a justificar tributação um pagamento de imposto menor para aqueles profissionais que atuam de forma individual em detrimento daqueles que atuam em forma de sociedade de profissionais. 


\section{CONSIDERAÇÕES SOBRE A INCONSTITUCIONALIDADE DO §2 DO ART. 414 DO \\ CÓDIGO TRIBUTÁRIO DO MUNICÍPIO DE SÃO LUÍS DE 2017}

Assim, os profissionais intelectuais que exercem suas atividades econômicas de forma individual em comparação àqueles que a exercem por meio de sociedade em nome coletivo não sofrem qualquer tipo de distinção no seu labor, salvo quando esta atuação se reveste na forma de empresa.

Com isto pode-se constatar a veracidade da primeira hipótese ventilada: o profissional intelectual que exerce sua atividade econômica por meio de sociedade de profissionais não se diferencia daquele que exerce de forma individual, uma vez que, a característica personalíssima da prestação de serviços, a responsabilidade do profissional em ambas as situações é ilimitada e pessoal, sendo que, até para fins de execução coletiva, a insolvência civil é o instituto utilizado, não havendo possibilidade recorrer à recuperação de empresas ou falência, por não ser considerado empresário.

Quanto à segunda hipótese, também, houve a confirmação de sua veracidade, uma vez que o Código Tributário do Município de São Luís, Estado do Maranhão, determina tratamento discriminatório entre contribuintes equivalentes - profissionais liberais que atuam individualmente e profissionais liberais que atuam sociedade simples em nome coletivo - no $\S 2^{\circ}$ do art. 414, logo, ferindo o inciso II do art. 150 da Constituição da República, bem como os art. 124, II da Constituição do Estado do Maranhão e no art. 107, II da Lei Orgânica do Município de São Luís.

O $\S 2^{\circ}$ do Art. 414 do CTM/SLZ ao estabelecer o tratamento diferenciado, toma por base a forma de organização do exercício da atividade econômica que, de fato e de direito, acaba por não alterar os elementos que compõem a relação de prestação de serviço, bem como, não existe nenhum critério que consiga justificar, à luz dos dispositivos constitucionais pátrios (seja na Constituição Federal, seja na Constituição do Estado do Maranhão ou mesmo na Lei Orgânica do Município de São Luís), a fixação de valores tributários diferenciados de R\$ 200,00 (duzentos) reais mensais para aqueles que não atuam em sociedade de profissionais isto é, de forma individual -, e de $\mathrm{R} \$ 684,59$ (seiscentos e oitenta e quatro reais e cinquenta e nove centavos) mensais para aqueles que atuam em sociedade de profissionais. Afinal de contas, ambas as categorias de contribuintes respondem ilimitadamente e pessoalmente por suas obrigações contraídas no exercício de sua atividade econômica, as quais, diga-se de passagem, 
não constituem elemento de empresa, em decorrência do caráter personalíssimo da prestação de serviços.

Desse modo, restou demonstrado que o $§ 2$ do art. 414 da Lei ${ }^{\circ}$ 6.289, de 28 de dezembro de 2017, quanto à incidência do ISSQN sobre a atividade dos profissionais intelectuais está eivada de inconstitucionalidade por ferir o inciso II do Art. 150 da Constituição da República (Princípio da Isonomia Tributária), uma vez que aplica tratamento diferenciado para contribuintes que se encontram em situação equivalente.

\section{REFERÊNCIAS}

ÁVILA, Humberto. TEORIA DA IGUALDADE TRIBUTÁRIA. São Paulo: Ed. Malheiros, 2009.

BRASIL. Constituição (1988). Constituição da República Federal do Brasil de 1988. Brasília,

DF, $1988 . \quad$ Disponível em:

$<$ http://www.planalto.gov.br/ccivil_03/constituicao/constituicao.htm>. Acesso em: 10 mar 2018.

Conselho Nacional de Justiça. Enunciado 194. Os profissionais liberais não são considerados empresários, salvo se a organização dos fatores de produção for mais importante que a atividade pessoal desenvolvida. Disponível em: <http://www.cjf.jus.br/enunciados/enunciado/374>. Acesso em: 10 mar 2018.

. Decreto-Lei ${ }^{\circ}$ 406, de 31 de dezembro de 1968. Estabelece normas gerais de direito financeiro, aplicáveis aos impostos sôbre operações relativas à circulação de mercadorias e sôbre serviços de qualquer natureza, e dá outras providências. Brasília, DF, 1968. Disponível em: < http://www.planalto.gov.br/CCivil_03/Decreto-Lei/Del0406compilado.htm>. Acesso em: 10 mar 2018.

. Lei 13.105, de 16 de março de 2015. Código de Processo Civil. Brasília, DF, 2015. Disponível em: <http://www.planalto.gov.br/ccivil_03/_ato2015-2018/2015/lei/l13105.htm>. Acesso em: 10 mar 2018.

. Lei Complementar $n^{\circ}$ 116/2003, de 31 de julho de 2003. Dispõe sobre o Imposto Sobre Serviços de Qualquer Natureza, de competência dos Municípios e do Distrito Federal, e 


\section{CONSIDERAÇÕES SOBRE A INCONSTITUCIONALIDADE DO §2 DO ART. 414 DO CÓDIGO TRIBUTÁRIO DO MUNICÍPIO DE SÃO LUÍS DE 2017}

dá outras providências. Brasília, DF, 2003. Disponível em: <http://www.planalto.gov.br/ccivil_03/leis/lcp/lcp116.htm>. Acesso em: 10 mar 2018.

. Lei Complementar $n^{\circ}$ 157, de 29 de dezembro de 2016. Altera a Lei Complementar no 116, de 31 de julho de 2003, que dispõe sobre o Imposto Sobre Serviços de Qualquer Natureza, a Lei no 8.429, de 2 de junho de 1992 (Lei de Improbidade Administrativa), e a Lei Complementar no 63, de 11 de janeiro de 1990, que “dispõe sobre critérios e prazos de crédito das parcelas do produto da arrecadação de impostos de competência dos Estados e de transferências por estes recebidos, pertencentes aos Municípios, e dá outras providências”. Brasília, DF, 2016. Disponível em: <http://www.planalto.gov.br/ccivil_03/leis/lcp/lcp157.htm>. Acesso em: 10 mar 2018.

Lei 8.906, de 16 de março de 1994. Dispõe sobre o Estatuto da Advocacia e a Ordem dos Advogados do Brasil (OAB). Brasília, DF, 2015. Disponível em: <http://www.planalto.gov.br/ccivil_03/Leis/L8906.htm>. Acesso em: 10 mar 2018.

Lei $\mathrm{n}^{\circ}$ 10.406/2002, de 10 de janeiro de 2002. Institui o Código Civil. Brasília, DF, 2002. Disponível em: <http://www.planalto.gov.br/ccivil_03/leis/2002/L10406compilada.htm>. Acesso em: 10 mar 2018.

Lei $\mathrm{n}^{0}$ 11.101/2015, de 09 de fevereiro de 2005. Regula a recuperação judicial, a extrajudicial e a falência do empresário e da sociedade empresária. Brasília, DF, 2005. Disponível em: <http://www.planalto.gov.br/ccivil_03/_ato2004-2006/2005/lei/l11101.htm>. Acesso em: 10 mar 2018.

. Lei $\mathrm{n}^{\circ}$ 5.869, de 11 de janeiro de 1973. Institui o Código de Processo Civil. Brasília, DF, 1973. Disponível em: <http://www.planalto.gov.br/ccivil_03/Leis/L5869impressao.htm>. Acesso em: 10 mar 2018.

. Superior Tribunal de Justiça. STJ. Agravo em Recurso Especial $n^{0}$ 1.006.254-SP (2016/0282555-8), Relator: Min. Raul Araújo. 17 abr 2017. Disponível: < https://stj.jusbrasil.com.br/jurisprudencia/450608486/agravo-em-recurso-especial-aresp1006254-sp-2016-0282555-8>. Acesso em: 10 mar 2018.

Supremo Tribunal Federal. Súmula $\mathbf{n}^{\circ}$ 663. Os $\S \S 1^{\circ}$ e $3^{\circ}$ do art. $9^{\circ}$ do Dl. 406/68 foram recebidos pela Constituição. Disponível: $<$ http://www.stf.jus.br/portal/jurisprudencia/listarJurisprudencia.asp?s1=663.NUME.\%20NA O\%20S.FLSV.\&base=baseSumulas>. Acesso em: 10 mar 2018. Supremo Tribunal Federal. $1^{\text {a }}$ Turma. Recurso Especial n. 992.266/RS, Rel. Min. Rafael Mayer. DJ 19/04/1983. 
Supremo Tribunal Federal. Pleno. Recurso Extraordinário n. 236.604-7/PR, Rel. Min.

$\begin{array}{llll}\text { Carlos Velloso. DJ 06/08/1999, Disponível: } & \text { DJ }\end{array}$ <phttp://redir.stf.jus.br/paginadorpub/paginador.jsp?docTP=AC\&docID=255615> . Acesso em: 10 mar 2018.

Supremo Tribunal Federal. Pleno. Recurso Extraordinário n. 220.323-3/MG, Rel.

$\begin{array}{llll}\text { Min. } & \text { Carlos } & \text { Velloso. } & \text { DJ }\end{array}$

$<$ http://redir.stf.jus.br/paginadorpub/paginador.jsp?docTP=AC\&docID=248997>. Acesso em: 10 mar 2018.

Supremo Tribunal Federal. 1ª Turma. Recurso Extraordinário n. 228.052-9/MG, Rel.

Min. Moreira Alves. DJ 01/10/1999, Disponível: $<$ http://redir.stf.jus.br/paginadorpub/paginador.jsp?docTP=AC\&docID=252412>. Acesso em: 10 mar 2018

. Supremo Tribunal Federal. $1^{\text {a }}$ Turma. Recurso Extraordinário n. 249.411-9/PR, Rel.

Min. Moreira Alves. DJ 08/10/1999, Disponível: $<$ http://redir.stf.jus.br/paginadorpub/paginador.jsp?docTP=AC\&docID=257875>. Acesso em: 10 mar 2018.

Superior Tribunal de Justiça. STJ. Agravo em Recurso Especial $n^{\circ}$ 1.006.254-SP (2016/0282555-8), Relator: Min. Raul Araújo. 17 abr 2017. Disponível: < https://stj.jusbrasil.com.br/jurisprudencia/450608486/agravo-em-recurso-especial-aresp1006254-sp-2016-0282555-8>. Acesso em: 10 mar 2018.

Superior Tribunal de Justiça. $2^{\text {a }}$ Turma. Recurso Especial n. 695500/MT, Rel. Min. Franciulli Netto. DJ 31/05/2006, p. 249.

Tribunal Regional Federal (3. Região). Agravo de Instrumento n. 002561176.2013.4.03.000, Relator: Des. Fed. Márcio Moraes, Dt. Julg: 03/04/2014, Terceira Turma. Disponível: < http://web.trf3.jus.br/acordaos/Acordao/BuscarDocumentoGedpro/3505115>. Acesso em: 10 mar 2018.

CARRAZZA, Roque Antonio. CURSO DE DIREITO CONSTITUCIONAL TRIBUTÁRIO. São Paulo: Ed. Malheiros, 2010.

MARANHÃO (Estado). Constituição (1988). Constituição do Estado do Maranhão de 1988. São Luís, $\quad$ MA, $1988 . \quad$ Disponível em: < http://www.stc.ma.gov.br/files/2013/03/CONSTITUI\%C3\%87\%C3\%83O-DO-ESTADODO-MARANH\%C3\%83O_atualizada_at\%C3\%A9_emenda69.pdf>. Acesso em: 10 mar 2018. 
MIRANDA, Pontes de. TRATADO DE DIREITO PRIVADO. 3ed. São Paulo: RT, 1984.

RAMOS, André Luiz Santa Cruz. CURSO DE DIREITO EMPRESARIAL: O novo regime jurídico-empresarial brasileiro. $4^{\mathrm{a}}$ Ed. Salvador: Editora JusPODIVM,2010.

SÃO LUíS (Município). Lei Orgânica do Município de São Luís. São Luís, MA, 2011. Disponível em: < http://camara.slz.br/lei-organica/?wpdmc=lei-organica>. Acesso em: 10 mar 2018.

Lei $n^{0}$ 6.289, de 28 de dezembro de 2017. Institui o Novo Código Tributário do Município de São Luís. Diário Oficial do Município de São Luís - MA, São Luís, MA, 28 dez 2017. N. 241.

SABAAG, Eduardo. Manual de Direito Tributário. $7^{\text {a }}$ ed. São Paulo: Saraiva, 2015.

SÃO PAULO (Estado). Tribunal de Justiça de São Paulo. Agravo de Instrumento n. 011057272.2013.8.26.0000, Rel. Luiz Ambra, Dt. Julg: 14/08/2013. Disponível: $<$ https://esaj.tjsp.jus.br/cposg/show.do?processo.foro=990\&processo.codigo=RI001SZRG000 0\#?cdDocumento=22>. Acesso em: 10 mar 2018.

SILVA, Edna Lúcia da. Menezes, Estera Muszkat. Metodologia da Pesquisa e Elaboração de Dissertação. UFSC. Programa de Pós-Graduação em Engenharia de Produção. Florianópolis, 2001.

TOMAZETTE, Marlon. CURSO DE DIREITO EMPRESARIAL: Teoria Geral e Direito Societário. São Paulo: Ed. Atlas, 2008.

UBALDO, Edson. INSOLVÊNCIA CIVIL: Questões controvertidas no processo de quebra voluntária. Florianópolis: Ed. Obra Jurídica, 2004. 